\title{
On the properties of the lactates
}

\section{Berzelius}

To cite this article: Berzelius (1832) On the properties of the lactates, Philosophical Magazine Series 2, 11:62, 151-152, DOI: 10.1080/14786443208647705

To link to this article: http://dx.doi.org/10.1080/14786443208647705

册Published online: 25 Jun 2009.

Submit your article to this journal 준

Џ Article views: 2

Q View related articles $\asymp$ 
brown, and gives a urinous smell; and when this has been succeeded by that of herring or roast meat, the mass is to be taken from the fire and treated with animal charcoal till it becomes colourless; it is then to be filtered, evaporated to dryness, and dissolved in alcohol ; the solution is to be decomposed by tartaric acid, the excess of which is to be removed by carbonate of lead, and the lead by sulphuretted hydrogen, and the residual solution then evaporated. In this way colourless acid is obtained, but it contains extractive matter, and is less pure than by the first method.

Lactic acid obtained by either of these methods is colourless, inodorous, has a sharp burning taste, which is quickly diminished by the addition of water; so that after having slightly diluted the acid, it has scarcely any taste. Evaporated at $212^{\circ}$ till it loses nothing more, the acid obtained with protoxide of tin flows with difficulty like a fat oil; that procured by the second process may be inverted in the containing vessel without learing it; both liquefy in the air; the first becomes fluid, the second syrupy. When strongly heated it becomes brown, boils slightly, and gives a suffocating smell like that of heated oxalic acid; it then blackens, swells, smells like burnt vegetable matter, and leaves a porous coal. It dissolves in alcohol in all proportions, but sparingly in ather.-Ann. de Chim. et de $P h$. xlvi. 420.

ON THE PROPERTIES OF THE LACTATES. BY THE SAME.

The lactates obtained by Scheele were all like gum and uncrystallizeable, except the lactates of magnesia and zinc, which may be crystallized; they are generally soluble in alcohol, but sometimes rather slowly, on account of the different extractive animal matters. When they contain an excess of base they dissolve with difficulty in alcohol, but readily when saturated. By destructive distillation they yield an acid liquor, the smell of which resembles that of the tartrates [pyrotartrates?], an inflammable oil and various gases. The lactate of potash prepared with lactic acid purified by protoxide of tin gives, when evaporated at $175^{\circ}$, a saline crystalline mass, which liquefies in the air.

Lactate of soda does not crystallize as long as the acid is in excess; but when it is saturated by carbonate of soda, dried and dissolved in alcohol evaporated at $154^{\circ}$, a crystallized salt is obtained, covered with a hard colourless transparent mass, which becomes moist in the air.

Lactate of ammonia, provided excess of ammonia be retained during the evaporation, exhibits traces of crystallization. The ammonia is dissipated, and leaves an acid deliquescent salt. By distillation it loses the greater part of its ammonia before it begins to decompose, as Scheele has already observed.

The lactates of barytes and lime are known only as non deliquescent transparent gummy masses : the magnesian salt, evaporated at a gentle heat, yields granular crystals, as Scheele has remarked; but by a mor 2 rapid evaporation it becomes a gummy non-deliquescent mass. The lactate of ammonia and magnesia crystallizes in acicular prisms, which do not alter in the air. It may be obtained 
by decomposing a solution of the magnesian salt with solution of ammonia, as long as precipitation takes place; then filter and evaporate. Lactate of lead is also a gummy salt; but having left a syrupy solution for a long time, a granular salt was obtained, which by drying became light and as brilliant as silver. It does not alter by exposure to the air, and dissolves in alcohol. In general lactic acid has the property of yielding a salt of lead, which is soluble in alcohol, a character by which it is distinguished from many other acids. When the neutral salt is decomposed by a small quantity of ammonia, a subsalt is precipitated; it is also obtained by digesting the neutral salt with an excess of oxide of lead, which swells up. The subsalt dissolves with difficulty in water; it is most frequently coloured with extractive matter; its aqueous solution is rendered turbid by the carbonic acid of the air, has an alkaline reaction, and an astringent taste. When it is boiled in water, and the boiling solvtion is filtered, the greater part of the salt is precipitated in the state of a light yellow powder. If this subsalt be dried, it becomes farinaceous and soft to the touch; and if it be ignited, it burns like amadou, and leaves metallic lead amounting to about ${ }_{1}^{8} 0^{3} 0$ of the salt employed.

Lactate of copper is green, and does not crystallize. According to Scheele the lactate of zinc crystallizes. The perlactate of iron is of a red brown colour; gummy and insoluble in alcohol. The protolactate of mercury is deliquescent, and dissolves in alcohol; but it is easily decomposed by it, yielding carbonate of mercury, and the liquid acquires an ethereal odour. The perlactate of mercury is red, gummy, and deliquescent. After some weeks it deposits a semicrystalline powder, which has not yet been examined. Lactate of silver is a soft transparent gumny mass, which has a disagreeable taste, is soluble in alcohol, and is slightly decomposed by it; it becomes greenish-yellow by drying, and red when redissolved in water; it then deposits a brown precipitate.

What has now been stated refers to lactates more or less mixed with alcoholic extract; they are yet unknown in a state of purity. Those who may occupy themselves with this subject in future, ought principally to direct their attention to determining whether what is called lactic acid is a mixture of two acids, which resemble each other, but which give different salts.-Ann. de Chim. et de Ph. xlvi. 420 .

ACETATE OF LEAD AND PYROACETIC SPIRIT. BY M. MATTEUCI.

Acetate of lead, when exposed to a gentle heat, begins to fuse at $136^{\circ}$ Fahr.; the liquid mass boils at $212^{\circ}$, and afterwards condenses into a very white mass at nearly the same heat. During this first fusion of the acetate of lend, it loses merely the three atoms of water which it contained. When heated above the temperature at which it becomes solid, it undergoes a second fusion, and at $536^{\circ}$ it is completely liquid. It boils for some time, and after having acquired a brownish colour, it again becomes solid, and has a dirty white colour, without any appearance of crystallization; this mass is trisa- 